\title{
Understanding Social and Environmental Hazards in Urban Areas: An Analysis from Barranquilla, Colombia
}

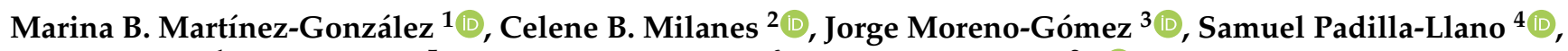 \\ Alex Vásquez ${ }^{1}$, Allan Lavell ${ }^{5}$, Ana Saltarín-Jiménez ${ }^{6}$ and Andrés Suárez ${ }^{2, *(D)}$ \\ 1 Department of Social Sciences, Universidad de la Costa, Barranquilla 080001, Colombia; \\ mmartine21@cuc.edu.co (M.B.M.-G.); avasquez2@cuc.edu.co (A.V.) \\ 2 GeMarc and GESSA Research Groups, Department of Civil and Environmental, Universidad de la Costa, \\ Barranquilla 080001, Colombia; cmilanes1@cuc.edu.co \\ 3 Department of Business Studies, Universidad de la Costa, Barranquilla 080001, Colombia; \\ jmoreno@cuc.edu.co \\ 4 Department of Arquitecture and Design, Universidad de la Costa, Barranquilla 080001, Colombia; \\ spadilla13@cuc.edu.co \\ 5 Facultad Latinoamericana de Ciencias Sociales (FLACSO), Curridabat 11801, Costa Rica; \\ allanmlavell@gmail.com \\ 6 Disaster Risk Management Office, Barranquilla 080003, Colombia; asaltari1@cuc.edu.co \\ * Correspondence: asuarez24@cuc.edu.co
}

Citation: Martínez-González, Marina B., Celene B. Milanes, Jorge Moreno-Gómez, Samuel Padilla-Llano, Alex Vásquez, Allan Lavell, Ana Saltarín-Jiménez, and Andrés Suárez. 2021. Understanding Social and Environmental Hazards in Urban Areas: An Analysis from Barranquilla, Colombia. Social Sciences 10: 411. https://doi.org/ 10.3390/socsci10110411

Academic Editor: Jason Enia

Received: 25 August 2021

Accepted: 12 October 2021

Published: 25 October 2021

Publisher's Note: MDPI stays neutral with regard to jurisdictional claims in published maps and institutional affiliations.

Copyright: (c) 2021 by the authors. Licensee MDPI, Basel, Switzerland. This article is an open access article distributed under the terms and conditions of the Creative Commons Attribution (CC BY) license (https:/ / creativecommons.org/licenses/by/ $4.0 /)$.

\begin{abstract}
The present research aims to understand the challenges faced by a Colombian city in the context of multidimensional risk scenarios, given the existing demographic and socio-economic conditions and local perspectives and perceptions regarding socio-environmental risks. The research was undertaken in the city of Barranquilla, northern Colombia. A survey was designed to analyze (1) the general socio-economic and vulnerability conditions of a communities' sample, (2) information related to hazards and disaster risk in their neighbourhoods, and (3) information on actions to mitigate risk. Three hundred and ninety-one people were surveyed. Likert scale and Pearson's Chi-square test and descriptive, inferential statistical methods, regression models, and the Mann-Whitney U test were used to process the results. Respondents lived, in general, under precarious socio-economic conditions (such as low income or lack of infrastructure and others). Given socio-environmental constraints, the research revealed that hazards such as urban stream flooding and robbery were the most negatively associated with the respondent's quality of life. Regarding the actions to avoid losses, $84 \%$ of respondents had not implemented any preventive action. Respondents also have low awareness of the need to implement risk prevention actions. Social risks and the configuration of anthropic hazards stand out as principal centres for concern.
\end{abstract}

Keywords: developing cities; quality of life; risk reduction; social vulnerability; sustainable development goals; urban poverty

\section{Introduction}

Floods, droughts, extreme temperatures, and storms are of concern to people and institutions (Hardoy and Pandiella 2009) because urban authorities in developing countries are obliged to consider the challenges and contribution of disaster risk to their plans for poverty reduction and economic growth (Choudhary et al. 2019). In this context, risk contributes a level of stress for vulnerable cities and populations that must make decisions facing many uncertainties (Hardoy and Pandiella 2009). The above is magnified by the conditions faced by cities located in the global south. (Choudhary et al. 2019). Therefore, there is widespread concern about the current and future implications of disaster risk for urban areas in developing countries, where cities proliferate most rapidly, and a high proportion of urban populations are poor (Tyler and Moench 2012). The above situation is what some authors call the 'double exposure' of cities in developing countries (Silver et al. 2013). 
The most impoverished countries and poorest people are most vulnerable because of a lack of sufficient means to adapt, mitigate and prevent, signifying that damage and loss are unequally distributed (De Sherbinin et al. 2007). One essential cause of disasters in developing cities is the uneven distribution of social and financial capital (Choudhary et al. 2019). Moreover, in urban areas where the land available for housing is unaffordable for low-income groups, the choices for a location with low exposure to natural hazards are limited (Hardoy and Pandiella 2009). Thus, urban expansion occurs in areas prone to hazards (Mavromatidi et al. 2018) such as landslides or flash floods.

The above-described context means that the most vulnerable groups (i.e., low-income groups in general, women, children, and the elderly) may often find their everyday struggles and difficulties compounded by the presence of disaster risk and disaster itself ${ }^{1}$. The emerging impacts of climate change and newer biotic and social hazards, together with the dangers inherent to the areas where cities are built, will increase the risk to these populations (Silver et al. 2013).

The vulnerability has an intrinsic association with people, places or things, regardless of whether they experience a hazard that may or may not cause harm (Carter et al. 2015).

Furthermore, vulnerability is the degree to which a system is likely to experience harm due to exposure to perturbations or stresses (Milanés Batista and Szlafsztein 2018; De Sherbinin et al. 2007) and is many times a pre-existing condition and an internal state (Leary et al. 2008). In this sense, social vulnerability is understood as the product of social stratification, social inequalities among different groups of people, and different environmental locations (Ge et al. 2017). Therefore, vulnerability is associated with several disadvantages in the context of social progress (Medina Pérez et al. 2019).

As disaster risks are strongly related to social vulnerability, impact assessment must be viewed from the perspective of society (Mavromatidi et al. 2018; Milanes et al. 2021). Increasing hazards and city growth call for strategies for the analysis of risk (including hazard, exposure and vulnerability factors) in urban areas (Zanetti et al. 2016) since this kind of assessment is needed to set up relevant disaster risk management and climate change adaptation policies (Yoo et al. 2011).

It is well known that urban areas today are home to $55 \%$ of the world's population (UNFPA 2018) and more than $80 \%$ of the Latin American and Caribbean population, and will continue growing for the next decades. In these circumstances, disaster risk is rapidly presenting additional obstacles for those subsisting and surviving under already poor living conditions in informal settlements (Dodman et al. 2018). The above evidence the scarse governability of these territories (Padilla-Llano 2015,2020) and threatens the quality of life of the citizens.

In this context, several authors have discussed the relationship between quality of life and disaster risk in vulnerable scenarios (Sarmiento and Torres-Muñoz 2020; Cui and Han 2018; Aihara et al. 2018; Khachadourian et al. 2015; Lin et al. 2002; Wang et al. 2000). As the quality of life is a multidimensional construct that includes at least physical capacity, psychological well-being, social relationships, and environment (Lin et al. 2002), disasters signify devastating physical and psycho-social impacts on human life (Ardalan et al. 2011). Therefore, this concept becomes perplexing in the context of complex urban networks, as the human component constitutes a social network itself (Bozza et al. 2015).

In the context of disaster risk management, disaster risk is influenced by broader national and global factors; however, it is shaped at the local level (Maskrey 2011). Moreover, identifying societal vulnerability is crucial for effective disaster risk management (Zhou et al. 2014). An interesting definition of vulnerability states that vulnerability is the unfavourable property of socio-ecological systems "which unfolds in the interaction between humans and nature, and it can be reduced by enhancing preparedness and promoting social learning" (Lei et al. 2014, p. 4). The role of the local population is topical for local disaster risk reduction because, despite socio-economic constraints, local people can respond, recover and deploy activities to face emergencies (Akter and Mallick 2013; Sandoval Díaz et al. 2018). They also can contribute to a significant reduction and prevention of 
risk factors, underlying causes and drivers of risk. Hence, the decision-making in disaster risk management has evolved from 'top-down approaches' to 'people-centred' approaches (Scolobig et al. 2015).

Given the former considerations, our research is framed in the context of the Sustainable Development Goals, mainly the 11th goal, 'Sustainable cities and communities.' The present paper is a result of the project 'Knowledge in Action for Urban Equality' (https:/ / www.urban-know.com/ accessed on 15 October 2021), which considers resilience, poverty and prosperity and promotes comparative inquiry for helping achieve civil equality in different countries and cities. The project challenges how communities across urban contexts similarly or differently experience or relate to poverty, prosperity and resilience.

The geographical conditions of Colombian cities and the growth and evolution of urban settlements have consolidated un-adapted cities for preventing multidimensional risk scenarios (Guo et al. 2018; Pardo Martínez 2018).

In this case, we present Barranquilla as a case study on Latin American cities' current process of growth and configuration and the challenges they face in integrating notions of development, prosperity, and quality of life into planning formats and actions. Furthermore, the need to analyze the reduction of social inequities that preceded risk situations in urban growth and how they could participate in disaster risk management at the local level are highlighted. In this sense, we expect to understand the challenges that developing cities face, where multidimensional risk scenarios are present, given the existing demographic and socio-economic conditions and local perspectives regarding socio-environmental vulnerabilities and hazards.

This work aimed to analyze the perception that citizens have of the threats to which they are exposed, determining how they affect their appreciation of the quality of life and the actions that people take to mitigate the risk in two localities of Barranquilla city. This city is the most affected by urban streams in South America, which occur every time it rains (Acosta-Coll et al. 2018). Moreover, landslides are characteristic of the southwestern side of the city and are exacerbated by the rainy season each year.

\section{Materials and Methods}

\subsection{Study Area}

The research was undertaken in the city of Barranquilla, one of the main cities of the country, located in northern Colombia (see Figure 1). The economic dynamics of the city at the end of the 19th century led to the rapid growth of the population, mainly through international migration (especially Germans, Americans, Italians, Spanish, Lebanese, Jews, among others), and through rural-urban migration. This two-pronged process led to the city's expansion following two distinct socio-economic patterns: the business elite to the northwest and the working-class neighbourhoods consolidated to the south of the city (Romero De Gutiérrez 2018). Land invasions also occurred, especially in the southwestern zone. These were transformed into subnormal neighbourhoods lacking essential public services. As the city grew, issues arose, such as informality, the inability of the administrations to generate development policies for the entire population, and the corruption that influenced the lack of social investment opportunities. Expansion towards the northwest occurred with the construction of housing and residential areas following planning dictates and norms for a population with more significant economic resources (Romero De Gutiérrez 2018).

The city is organized into 5 administrative units, Riomar, Norte Centro Histórico, Metropolitana, Suroriente and Suroccidente. For the present study, historically populated neighbourhoods located in high-risk areas on the periphery of the city were selected. Two areas (localities) were selected; one located on the hillside of the Magdalena River in the north-eastern area-Riomar Locality (RML), and the other on the southwestern slope-the Suroccidente Locality (SOL) (see Figure 1). RML is characterized by a marked inequality in socio-economic characteristics, urban endowment, and exposure to disaster risks. On the 
other hand, the SOL is characterized by poor socio-economic conditions, and a significant part of the population is affected by landslides, urban pluvial streams, and flooding.
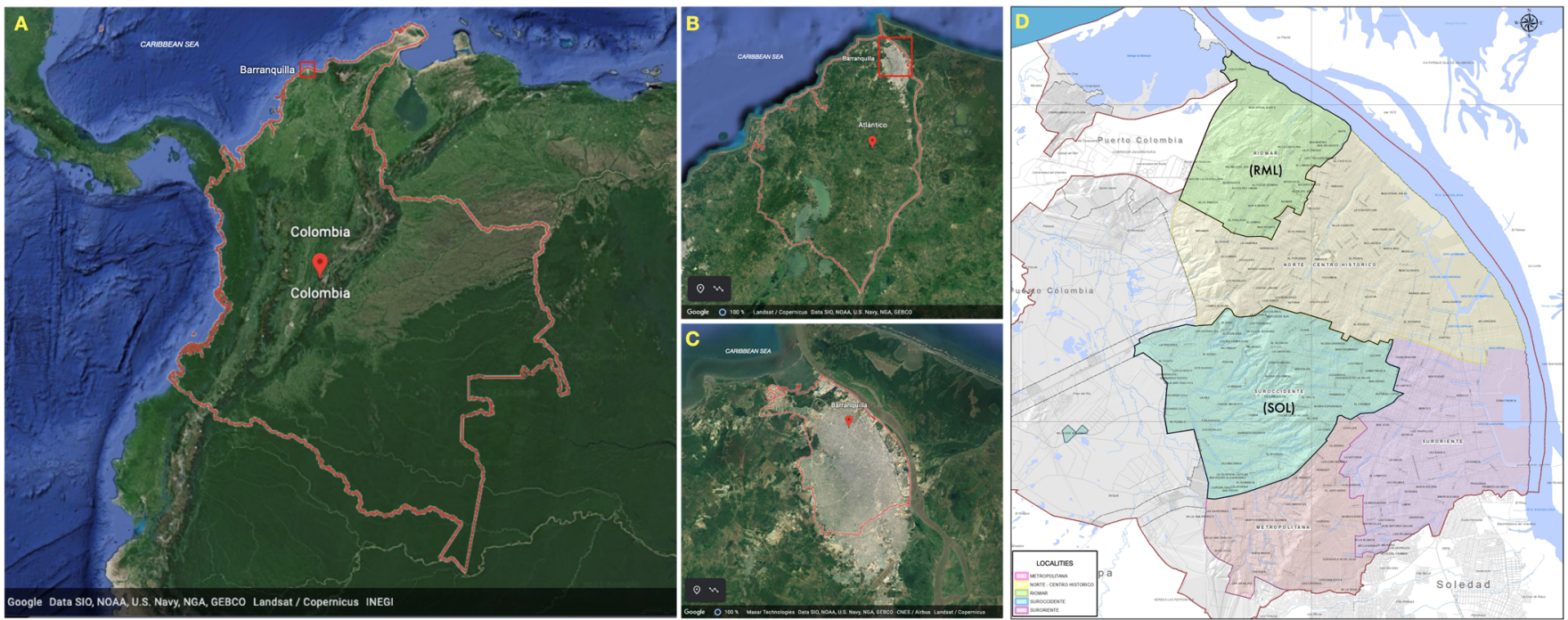

Figure 1. (A). Barranquilla city's location at the Republic of Colombia; (B). Atlántico department and its capital Barranquilla; (C). Barranquilla city. Scheme 2021, accessed on 25 August 2021. (D). Riomar (RML) and Suroccidente (SOL), localities of the city of Barranquilla focused on the study. Source: adapted from Plan de Ordenamiento Territorial de Barranquilla 2012-2032.

\subsection{Study Design}

A survey was designed in order to analyze (1) the general socio-economic and vulnerability conditions of those interviewed; (2) information related to hazards and disaster risk in the neighbourhoods; and (3) information on actions taken to mitigate risk. A purposive sample of 25 people from the SOL answered a preliminary version of the survey, where a semantic validation of the items was undertaken. Additionally, correlations were made between the items on the scale that allowed identifying those most relevant and conditioned to one another. The scales of some questions were clarified, and questions that were difficult for the community to understand were deleted. Moreover, MacDonald's $\omega(0.65)$ and Guttman's $\lambda 6(0.72)$ were used to estimate the final reliability of the questionnaire.

The survey comprised 20 questions and three sections (see Supplementary Materials Table S1 for details). Paper-based and random door to door questionnaires were distributed among 391 people. A sampling approach was chosen, initially based on clusters (neighbourhoods) and then through simple random sampling, according to the proportion of the population in each associated neighbourhood $(\mathrm{SOL}=135 ; \mathrm{RML}=256)$.

\subsection{Data Analysis}

Data analysis was achieved through descriptive, inferential statistical methods (SPSS $\left.25^{\circledR}\right)$ and regression models (STATA $\left.14^{\circledR}\right)$. Pearson's Chi-square test $(p<0.05 ; p<0.10)$ was applied to identify significant differences between different variables in the study locations (RML and SOL). Additionally, the Mann-Whitney U test $(p<0.05)$ was applied to identify significant differences regarding social welfare levels in the neighbourhood vs. the perceptions of various hazards amongst the population in each locality. Finally, an adjusted (multivariate) and unadjusted (bivariate) logistic model was applied to analyze the correlation between the self-reported perception on the existence of a good quality of life (yes/no) and social and environmental hazards in the study area. 


\section{Results}

\subsection{General Information about Socioeconomic Characteristics}

Of the 391 respondents (see detailed results in Table 1), 60\% were women. The average age of the respondents was 39 years (S.D. = 14). Sixty-five per cent of the respondents belong to the locality of RML, and the remaining 35\% to SOL. Furthermore, $69 \%$ of respondents in the SOL were unemployed, while in RML, unemployment was $52 \%$. Household occupancy consisted of four to six people (57\%), and the family nucleus was made up of an average of four people per household.

Table 1. General socio-economic information.

\begin{tabular}{|c|c|c|c|c|c|}
\hline Variable & Frequency & $\%$ & Variable & Frequency & $\%$ \\
\hline Gender & & & Educational level & & \\
\hline Male & 152 & 39 & None & 15 & 3.8 \\
\hline Female & 234 & 60 & Elementary & 101 & 25.8 \\
\hline $\begin{array}{l}\text { Monthly incomes } \\
\text { (USD) * }\end{array}$ & & & Baccalaureate & 174 & 44.5 \\
\hline$\$ 0-103.23$ & 131 & 33.5 & Technical study & 62 & 15.9 \\
\hline$\$ 104-213.61$ & 138 & 35.3 & Undergraduate & 14 & 3.6 \\
\hline$\$ 214-438.71$ & 76 & 19.4 & Graduate & 24 & 6.1 \\
\hline$>\$ 439$ & 14 & 3.6 & Good quality of life & & \\
\hline SISBEN ** & & & Not & 156 & 39.9 \\
\hline Not & 98 & 25.1 & Yes & 232 & 59.3 \\
\hline Yes & 292 & 74.7 & & & \\
\hline
\end{tabular}

Sixty-eight per cent of respondents have incomes under 214 USD a month. The predominant educational level was high school (44\%). For the most part, respondents had access to basic public services (street cleaning $=92 \%$; water supply $=96 \%$; electricity $=98 \%$; household gas $=81 \%$; sewage system $=82 \%$ ); other services were scarcer such as cell phone $(28 \%)$, landline phones $(28 \%)$ and internet $(42 \%)$.

An important research finding relates to the good quality of life (GQL) perceived in the neighbourhoods. The results show that $60 \%$ affirmatively claim to have a GQL. However, the Pearson's Chi-square test showed a significant difference between the quality of life perceived in the two localities $(p=0.003)$; thus, the SOL presented a higher proportion of people who said they did not have GQL $(\mathrm{SOL}=55 \%$; $\mathrm{RML}=45 \%$ ).

The survey revealed interesting aspects related to social welfare levels in the neighbourhoods (Table 2). Thus, for example, travel times to places where respondents obtained essential services was established. The estimated average times to access medical services were for general medicine, $31 \mathrm{~min}$, specialized medicine, $37 \mathrm{~min}$, and emergency services, $27 \mathrm{~min}$. Additionally, the aspects that most contributed to welfare were established through the Likert scale (score of 1-10).

Table 2. Aspects related to the quality of life.

\begin{tabular}{cccc}
\hline Items & Mean & Dev. Est. & Median \\
\hline Quality in public services & 5.9 & 2.8 & 6 \\
Closeness to the workplace & 6.1 & 3.4 & 7 \\
Closeness to health services & 7.0 & 2.6 & 8 \\
Access to public transportation & 8.0 & 2.5 & $9 *$ \\
Closeness to education services & 8.4 & 2.1 & $9 *$ \\
Feeling of security & 4.4 & 3.1 & 4 \\
Cultural activities & 4.5 & 3.3 & $4^{*}$ \\
Relationship with neighbours & 8.1 & 2.5 & 9 \\
Closeness to recreation areas such as parks or courts & 7.4 & 3.1 & $9^{*}$
\end{tabular}

* We identified through the Mann-Whitney $U$ test that RML had higher values in the qualification of access to transport $(p=0.000)$, access to educational services $(p=0.033)$, cultural activities $(p=0.001)$, and proximity to recreation areas $(p=0.000)$. 
It is evident from the information provided in the previous table that the aspects that least contributed to the quality of life of the respondents were the negative sense of security $(4 / 10)$ and the lack of cultural activities $(4 / 10)$. On the other hand, the aspects that contribute most to the quality of life were access to collective services or goods (access to public transport $=9 / 10$, proximity to education services $=9 / 10$, proximity to recreation areas such as park or courts $9 / 10$; closeness to health services $=8 / 10$ and closeness to work $=7 / 10$ ).

\subsection{Information Related to Socio-Environmental Hazards and Disaster Risk}

The identification of social and environmental hazards in the neighbourhoods was attempted, considering their recurrence (Table 3). It is noteworthy that the most frequent hazard identified was drug addiction $(85 \%)$, followed by robbery $(63 \%)$, urban streams or floods $(39 \%)$, and homicides $(24 \%)$. That is to say, social hazards are more important in the population's life view than physical hazards, thus confirming the analysis presented in the introduction.

Table 3. Information related to the frequency of hazards in the neighbourhoods (see Supplementary Materials Table S2 for analysis in each neighbourhood).

\begin{tabular}{|c|c|c|c|c|c|}
\hline \multicolumn{3}{|c|}{ Environmental Hazards } & \multicolumn{3}{|c|}{ Social Hazards } \\
\hline Variable & $\mathbf{Q}$ & $\%$ & Variable & $\mathbf{Q}$ & $\%$ \\
\hline Fires & & & Drug addiction & & \\
\hline Never & 266 & 68.0 & Never & 26 & 6.8 \\
\hline Sometimes & 112 & 28.6 & Sometimes & 33 & 8.6 \\
\hline Frequently & 10 & 2.6 & Frequently & 323 & 84.6 \\
\hline Urban streams & & & Sexual abuse & & \\
\hline Never & 145 & 37.1 & Never & 240 & 61.4 \\
\hline Sometimes & 94 & 24.0 & Sometimes & 125 & 32.0 \\
\hline Frequently & 152 & 38.9 & Frequently & 22 & 5.6 \\
\hline Earthquakes & & & Robbery & & \\
\hline Never & 355 & 90.8 & Never & 34 & 8.7 \\
\hline Sometimes & 36 & 9.2 & Sometimes & 111 & 28.4 \\
\hline Landslides & & & Frequently & 246 & 62.9 \\
\hline Never & 360 & 92.1 & Homicides & & \\
\hline Sometimes & 28 & 7.2 & Never & 121 & 30.9 \\
\hline Frequently & 3 & 0.8 & Sometimes & 174 & 44.5 \\
\hline Vector diseases & & & Frequently & 95 & 24.3 \\
\hline Never & 159 & 40.7 & & & \\
\hline Sometimes & 156 & 39.9 & & & \\
\hline Frequently & 68 & 17.4 & & & \\
\hline
\end{tabular}

Fifteen per cent of the respondents indicated that they had suffered losses due to previously occurring disaster events. Regarding the actions generated to avoid loss, $4 \%$ stated they received training for emergency management, $2 \%$ changed their place of residence to mitigate or avoid hazards, and $84 \%$ had not developed any preventive action.

Regarding the perception of respondents about their vulnerability to different hazards (1-4 scale), the types of hazards that generated higher values were: drug addiction (4/4) and robbery $(3 / 4)$. Under certain circumstances, social hazards can also be seen as a vulnerability when faced with other hazards. For example, drug addiction and robbery can be seen as hazards, but depending on where they occur, they can increase the vulnerability to natural hazards, such as flooding and landslides. Their presence may inhibit persons acting consequently due to feelings of insecurity that reduce their willingness to invest in their homes. As mentioned by Lavell et al. (2012) "disaster signifies extreme impacts suffered when hazardous physical events interact with vulnerable social conditions to severely alter the normal functioning of a community or a society" (p. 1).

The remaining values were in the middle to low ranges. Urban streams $(2 / 4)$, homicides $(2 / 4)$, sexual abuse $(2 / 4)$, and illness $(2 / 4)$ were rated with intermediate values. The 
respondents rated fires, earthquakes, and landslides with low values (1/4). Concerning the differences in the perceptions of the inhabitants of the two localities, it was found that there were significant differences between these, with higher values for urban streams $(p=0.024)$, landslides $(p=0.000)$, and robbery $(p=0.000)$ in the SOL.

Table 4 depicts a bivariate and multivariate correlation between the respondents' perceptions of QGL and the values assigned to the hazards. The results indicate that in the bivariate analysis, hazards such as urban streams, landslides, robbery, and drug addiction significantly influenced respondents' perceptions about GQL. On the other hand, in the multivariate analysis, when the dependent variable was controlled, only socio-environmental hazards such as urban streams and robbery negatively influenced the respondent's GQL. The remaining hazards were not statistically significant in the adjusted model.

Table 4. Factors influencing respondent's perceptions of good quality of life.

\begin{tabular}{ccccccccc}
\hline \multirow{2}{*}{ Dependent Variable } & \multicolumn{3}{c}{ Good Quality of Life } \\
\cline { 2 - 8 } & \multicolumn{3}{c}{ Unadjusted (Bivariate) } & \multicolumn{4}{c}{ Adjusted (Multivariate) } \\
\hline Independent Variables & Coef. & Std. Err. & $\mathbf{z}$ & $\mathbf{P}>\mathbf{z}$ & Coef. & Std. Err. & $\mathbf{z}$ & $\mathbf{P}>\mathbf{z}$ \\
\hline Fires & & & & & -0.07480 & 0.136 & -0.55 & 0.584 \\
Urban streams & -0.76361 & 0.129 & -5.89 & $0.000^{*}$ & -0.77290 & 0.138 & -5.57 & $0.000^{*}$ \\
Earthquake & & & & & -0.09057 & 0.391 & -0.23 & 0.817 \\
Landslides & -0.60569 & 0.336 & -1.80 & $0.072 * *$ & -0.13143 & 0.368 & -0.36 & 0.721 \\
Homicides & & & & & 0.055201 & 0.132 & 0.42 & 0.676 \\
Heists & -0.86386 & 0.188 & -4.59 & $0.000 *$ & -0.98023 & 0.206 & -4.75 & $0.000 *$ \\
Sex_abuse & & & & & -0.01474 & 0.012 & -1.14 & 0.255 \\
Drugs & -0.01864 & 0.008 & -2.17 & $0.030 * *$ & -0.01458 & 0.009 & -1.54 & 0.125 \\
Illness_vectors & & & & & 0.00782 & 0.008 & 0.90 & 0.369 \\
_cons & & & & & 4.8875 & 0.807 & 6.06 & 0.000 \\
\hline
\end{tabular}

Sig. ${ }^{*} p<0.00 ;{ }^{* *} p<0.05 ;{ }^{* * *} p<0.10$.

\subsection{Information Related to Actions to Mitigate Socio-Environmental Risk and as to Social Participation}

This section discusses the extent to which respondents recognized the existence of installed capacities and knowledge as to what to do when facing threatening events in their neighbourhoods. Survey results show that only $11 \%$ of respondents were part of a social organization, and $9 \%$ have been part of projects for risk prevention. On the other hand, as regards response capacities, $50 \%$ had telephone contacts with the police, and $60 \%$ knew the lines for accessing emergency care. Concerning their knowledge about what to do in case of an emergency related to physical hazards, 55\% of respondents said they did not know what to do. A Chi-square test did not show a significant association between respondents having been part of projects for risk prevention and what to do in case of an emergency $(p>0.05 ; p=0.06)$. Likewise, $71 \%$ of the participants reported knowledge of preventive actions for vector related diseases.

\section{Discussion}

\subsection{Socio-Environmental Context of Vulnerability}

Survey results depict a context of socio-environmental vulnerabilities and hazards that comprise risk situations in urban growth and are significant in considering the necessary conditions for promoting successful disaster risk management at the local level. The questionnaire results revealed that the socio-economic conditions of the respondents are precarious (Table 2). High unemployment (60\%), low levels of income (68\% earn one MCLW or less), and high levels of dissatisfaction with the quality of life (bad quality $=40 \%$ ) can be highlighted here. The above findings are particularly relevant in the SOL, where the perception about the GQL is lower than in the RML $(p=0.003)$. Moreover, results depict significantly lower levels of welfare in the SOL neighbourhoods (Table 2). In this sense, 
results are in line with findings that report serious challenges related to the respondent's living conditions, where several socio-economic constraints exist (Goryoda et al. 2019). They also reinforce the statement that socio-economic issues significantly impact the quality of life in vulnerable environments (Chacowry 2016).

The relationship between the quality of life of the respondents and the hazards they identified revealed that some environmental and social aspects have a negative correlation with the respondents living conditions both in bivariate and multivariate analyses (Table 4). In this line of analysis, some researchers have discussed the relationship between living conditions and single environmental hazards such as earthquakes (Cui and Han 2018; Giuliani et al. 2014; Lin et al. 2017), tsunamis (Peters et al. 2016), or landslides (Nathan 2008). However, a broader and integrative perspective is proposed here as more than one environmental aspect was analyzed, while more aspects of context were also analyzed, including social and environmental dimensions. This approach shed light on the multidimensional hazards present in a developing city, such as Barranquilla, and their relationships.

\subsection{Perceptions about Hazards and Risk Environments}

One outstanding aspect of the project results refers to the respondents' exposure to hazards. It relates both to frequency and the associated perception of danger. In this sense, results suggest that the most threatening aspects are anthropic and related to citizen security. Results indicate that the perception of hazard is related to social aspects (Cid Ortiz et al. 2012) and highlights the fact that people's perceptions of hazards are both socially constructed (i.e., contextual) and subjective (Adomah Bempah and Olav Øyhus 2017).

The respondents rated low-risk for most of the 'environmental' hazards (i.e., fires, earthquakes, and landslides). However, in SOL, urban streams and landslides were more highly rated than in RML. This result relates to the higher levels of exposure of the inhabitants in the SOL to these phenomena and draws attention-as other research has done- to the levels of awareness of urban streams flooding (Adomah Bempah and Olav Øyhus 2017; Bodoque et al. 2016; Lara et al. 2017) and landslides (Cid Ortiz et al. 2012; Li et al. 2019). In this context, social perception is essential because it helps managers understand communities' physical and social world (Adomah Bempah and Olav Øyhus 2017) and highlights the importance of social perceptions according to the multidimensional hazards of their local context.

Other studies that seek to integrate risk management perspectives, adaptation to climate change, and city planning, have found the relevance of social aspects in the construction of resilient cities. An example of this is the City Resilience Framework project developed by ARUP with support from the Rockefeller Foundation in six cities (Cali, Colombia; Concepción, Chile; New Orleans, USA; Cape Town, South Africa; Surat, India; and Semarang, Indonesia). They have found that the concerns and priorities about the city's functioning among the most vulnerable groups are very different from those of the government and the private sector. Similarly, they have perceived a clear distinction between cities that had experienced shocks and those that had not. Even different groups within the same city had different perspectives and priorities on what makes their city resilient.

However, based on the experiences of those six cities, a certain level of agreement has been reached regarding what would be the characteristics of a resilient city: minimal human vulnerability; diverse livelihoods and employment; effective safeguards to human health and life; collective identity and community support; comprehensive security and rule of law; sustainable economy; reduced exposure and fragility; effective provision of critical services; reliable communications and mobility; effective leadership and management empowered stakeholders; and integrated development planning. On the contrary, a territory characterized by ill-health or insecurity, an unsafe environment, conflict, and deprivation would be a non-resilient city (ARUP and The Rockefeller Foundation 2014).

The relevance attributed by the participants in this study to social hazards reflects a perspective that goes beyond the delimitation of disaster risk associated with physical 
threats and constitutes an opportunity to integrate the reduction of inequality and risk management in city development planning policies.

\subsection{Social Awareness and Preparedness for Disaster Risks}

Risk awareness and preparedness can affect people's vulnerability since poor consciousness may exacerbate vulnerability considerably (Ainuddin and Kumar Routray 2012). In this context, survey results illustrate that the community in the two studied localities have a poor knowledge base to face hazards. Just $4 \%$ have been trained in emergency management, $2 \%$ have changed their residence, $84 \%$ have not developed any preventive action. Furthermore, only $9 \%$ have been part of projects for risk prevention, and $45 \%$ stated that 'they would know' what to do in case of a disaster. A shallow level of preparedness for emergencies was found ( $4 \%$ ), contrary to other research that found more than $20 \%$ in social training for emergencies (Castro et al. 2017). Even the values of 'what to do' facing emergencies are very low compared to results provided by other studies that found above $50 \%$ of the population were cognizant of what to do (see Bodoque et al. 2016, for example). Regarding the above, some authors stress that due to varying socio-economic conditions, the community perception about risk and their consequences-and actions-may vary (Rehman et al. 2019). Furthermore, residents' awareness of disaster risk reduction is an essential factor influencing their behavioural decisions (Xu et al. 2019). Attention must be paid to people's interpretations of risks, shaped by their own experience, feelings, values, cultural beliefs, and interpersonal and social dynamics (Eiser et al. 2012). The lack of human and technical resources produces poor disaster awareness and an ineffective implementation of prevention and mitigation strategies at the local levels (Ainuddin et al. 2013).

\section{Conclusions}

The aspects that stand out from the results were social vulnerability and the configuration of anthropic hazards. The elements that contribute most to the welfare in the neighbourhoods were those related to access to public goods and services that contribute to the reduction of social vulnerability. Similarly, the low levels of social awareness in the localities to face the multidimensional hazards must be highlighted. For this reason, subsequent research and policy development is necessary to encourage and develop citizen empowerment and participation schemes, which allow greater consolidation of the pathways along which plans, programs, and projects for risk prevention or mitigation can be structured. This means that it is not only important to have a presence in the decisionmaking places but that it is essential to promote and stimulate an active and dynamic role in the structuring and vision of local development (Remesar et al. 2012).

In the comparative analysis between localities, the SOL had higher degrees of vulnerability, not only because it presented proportionally higher levels of unemployment and poverty but also because the results showed that respondents did not perceive a GQL of life in the locality due to the absence of public services and collective goods when compared to RML. Furthermore, in the RML, higher levels of perception related to hazards existed, particularly those related to events such as urban stream flooding, landslides, and robbery.

The present article is a contribution to SDG 11.7.(A) - Strengthen national and regional development planning, and support positive economic, social and environmental links between urban, peri-urban, and rural areas by strengthening national and regional development planning. This context poses a substantial challenge from the perspective of social vulnerability management and the promotion of strategies aimed at including these communities in processes oriented to generate installed capacities and their inclusion in the city-development plans.

Supplementary Materials: The following are available online at https://www.mdpi.com/article/10 .3390 / socsci10110411/s1, Table S1: Description of the study variables, Table S2: Information related to the perceived frequency of hazards in each neighbourhood. 
Author Contributions: Conceptualization, M.B.M.-G., A.S., A.L., C.B.M.; methodology, A.S., M.B.M.G., C.B.M.; validation, M.B.M.-G., A.S.; investigation, M.B.M.-G., A.S., C.B.M., A.V., A.S.-J., A.L.; resources, A.L., J.M.-G., A.S.-J.; writing-original draft preparation, A.S., M.B.M.-G., C.B.M., S.P.-L., A.L., writing-review and editing, M.B.M.-G., A.S., C.B.M., A.L.; supervision, A.L., J.M.-G., M.B.M.G.; project administration, J.M.-G., A.L.; funding acquisition, A.L., J.M.-G., A.S.-J. All authors have read and agreed to the published version of the manuscript.

Funding: This research was funded by the Project "Knowledge in Action for Urban Equality-KNOW" Coordinated by the Development Planning Unit of University College London and by the UK Economic and Social Research Council (ESCR) under the Global Challenges Research Fund (GCRF). The research leading to the present article was undertaken in the frame of Work Package 2 on resilience, poverty, and prosperity, developed by research teams in Colombia, Costa Rica and Peru under the coordination of Allan Lavell.

Institutional Review Board Statement: The study was conducted according to the guidelines of the Declaration of Helsinki. Ethical review and approval were waived for this study because the procedures performed do not imply any risk for the participants who voluntarily answered the surveys. The information was handled anonymously, respecting the data protection laws of Colombia.

Informed Consent Statement: Informed consent was obtained from all subjects involved in the study.

Data Availability Statement: Data supporting reported results can be found asking directly of the first author.

Acknowledgments: Our sincere thanks to all the coordinators, funders, and researchers involved in the KNOW project, as well as to all key informants and the Risk Management Office from Barranquilla and participants in the co-production research process.

Conflicts of Interest: The authors declare no conflict of interest.

\section{Note}

1 Disaster risk, seen as a latent condition, signifies that communities in such areas often do not invest in their houses or infrastructure. At the same time, many local governments are normatively limited in the investments they can make in their territories. The disaster itself leads to loss of the investments made and little chance of their recovery.

\section{References}

Acosta-Coll, Melisa, Francisco Ballester-Merelo, and Marcos Martínez-Peiró. 2018. Early warning system for detection of urban pluvial flooding hazard levels in an ungauged basin. Natural Hazards 92: 1237-65. [CrossRef]

Aihara, Yoko, Sadhana Shrestha, Sudarshan Rajbhandari, Arun Prasad Bhattarai, Niranjan Bista, Futaba Kazama, and Junko Shindo. 2018. Resilience in household water systems and quality of life after the earthquake: A mixed-methods study in urban Nepal. Water Policy 205: 1013-26. [CrossRef]

Ainuddin, Syed, and Jayant Kumar Routray. 2012. Community resilience framework for an earthquake prone area in Baluchistan. International Journal of Disaster Risk Reduction 2: 25-36. [CrossRef]

Ainuddin, Syed, Daniel P. Aldrich, Jayant K. Routray, Shabana Ainuddin, and Abida Achkazai. 2013. The need for local involvement: Decentralization of disaster management institutions in Baluchistan, Pakistan. International Journal of Disaster Risk Reduction 6: 50-58. [CrossRef]

Akter, Sonia, and Bishawjit Mallick. 2013. The poverty-Vulnerability-Resilience nexus: Evidence from Bangladesh. Ecological Economics 96: 114-24. [CrossRef]

Ardalan, Ali, Monir Mazaheri, M. Vanrooyen, H. Mowafi, S. Nedjat, K. H. Naieni, and M. Russel. 2011. Post-disaster quality of life among older survivors five years after the Bam earthquake: Implications for recovery policy. Ageing and Society 312: 179-96. [CrossRef]

ARUP and The Rockefeller Foundation. 2014. City Resilience Framework. The Rockefeller Foundation and ARUP 928. Available online: https: / www.urban-response.org/system/files/content/resource/files/main/city-resilience-framework-arup-april2014.pdf (accessed on 25 August 2021).

Adomah Bempah, Sherry, and Arne Olav Øyhus. 2017. The role of social perception in disaster risk reduction: Beliefs, perception, and attitudes regarding flood disasters in communities along the Volta River, Ghana. International Journal of Disaster Risk Reduction 23: 104-8. [CrossRef] 
Bodoque, José María, María Amérigo, Andrés Díez-Herrero, Juan A. García, Beatriz Cortés, Juan Antonio Ballesteros-Cánovas, and Jorge Olcina. 2016. Improvement of resilience of urban areas by integrating social perception in flash-flood risk management. Journal of Hydrology 541: 665-76. [CrossRef]

Bozza, Anna, Domenico Asprone, and Gaetano Manfredi. 2015. Developing an integrated framework to quantify resilience of urban systems against disasters. Natural Hazards 783: 1729-48. [CrossRef]

Carter, Jeremy G., Gina Cavan, Angela Connelly, Simon Guy, John Handley, and Aleksandra Kazmierczak. 2015. Climate change and the city: Building capacity for urban adaptation. Progress in Planning 95: 1-66. [CrossRef]

Castro, Carmen-Paz, Juan-Pablo Sarmiento, Rosita Edwards, Gabriela Hoberman, and Katherine Wyndham. 2017. Disaster risk perception in urban contexts and for people with disabilities: Case study on the city of Iquique Chile. Natural Hazards 86: 411-36. [CrossRef]

Chacowry, Anoradha. 2016. Public perceptions of living with flood risk from media coverage in the small island developing state of Mauritius. International Journal of Disaster Risk Reduction 19: 303-10. [CrossRef]

Choudhary, Bikramaditya K., Arun Kumar Tripathi, and Jeetesh Rai. 2019. Can 'poor'cities breathe: Responses to climate change in low-income countries. Urban Climate 27: 403-11. [CrossRef]

Cid Ortiz, Guillermo, Carmen Castro Correa, and Vanessa Rugiero de Souza. 2012. Percepción del riesgo en relación con capacidades de autoprotección y autogestión, como elementos relevantes en la reducción de la vulnerabilidad en la ciudad de la Serena. INVI 75: 105-42. [CrossRef]

Cui, Ke, and Ziqiang Han. 2018. Association between disaster experience and quality of life: The mediating role of disaster risk perception. Quality of Life Research 282: 509-13. [CrossRef]

De Sherbinin, Alex, Andrew Schiller, and Alex Pulsipher. 2007. The vulnerability of global cities to climate hazards. Environment and Urbanization 191: 39-64. [CrossRef]

Dodman, David, Diane Archer, and Marcus Mayr. 2018. Addressing the Most Vulnerable First: Pro-Poor Climate Action in Informal Settlements. Nairobi: UN-Habitat. Available online: https://unhabitat.org/pro-poor-climate-action-in-informal-settlement (accessed on 25 August 2021).

Eiser, J. Richard, Ann Bostrom, Ian Burton, David M. Johnston, John McClure, Douglas Paton, Joopvan der Pligt, and Mathew P. White. 2012. Risk interpretation and action: A conceptual framework for responses to natural hazards. International Journal of Disaster Risk Reduction 1: 5-16. [CrossRef]

Ge, Yi, Wen Dou, and Ning Liu. 2017. Planning resilient and sustainable cities: Identifying and targeting social vulnerability to climate change. Sustainability 98: 1394. [CrossRef]

Giuliani, Anna R., Antonella Mattei, Flavio Santilli, Giovanna Clori, Maria Scatigna, and Leila Fabiani. 2014. Well-Being and Perceived Quality of Life in Elderly People Displaced After the Earthquake in L'Aquila, Italy. Journal of Community Health 39: 531-37. [CrossRef]

Goryoda, Sayuri, Nobuo Nishi, Haruki Shimoda, Yuki Yonekura, Kiyomi Sakata, Seiichiro Kobayashi, Akira Ogawa, and Ichiro Kawachi. 2019. Social Capital and Dietary Intakes Following the 2011 Great East Japan Earthquake and Tsunami. Journal of Epidemiology 293: 92-96. [CrossRef]

Guo, Yuming, Antonio Gasparrini, Shanshan Li, Francesco Sera, Ana Maria Vicedo-Cabrera, Micheline de Sousa Zanotti Stagliorio Coelho, Paulo Hilario Nascimento Saldiva, Eric Lavigne, Benjawan Tawatsupa, Kornwipa Punnasiri, and et al. 2018. Quantifying excess deaths related to heatwaves under climate change scenarios: A multicountry time series modelling study. PLoS Medicine 15: e1002629. [CrossRef]

Hardoy, Jorgelina, and Gustavo Pandiella. 2009. Urban poverty and vulnerability to climate change in Latin America. Environment and Urbanization 21: 203-24. [CrossRef]

Khachadourian, Vahe, Haroutune K. Armenian, Anahit Demirchyan, and Armen Goenjian. 2015. Loss and psychosocial factors as determinants of quality of life in a cohort of earthquake survivors. Health and Quality of Life Outcomes 131: 13. [CrossRef]

Lara, Alejandro, Xavier Garcia, Felipe Bucci, and Anna Ribas. 2017. What do people think about the flood risk? An experience with the residents of Talcahuano city, Chile. Natural Hazards 85: 1557-75. [CrossRef]

Lavell, Allan, Michael Oppenheimer, Cherif Diop, Jeremy Hess, Robert Lempert, Jianping Li, Robert Muir-Wood, Soojeong Myeong, Susanne Moser, Kuniyoshi Takeuchi, and et al. 2012. Climate change: New dimensions in disaster risk, exposure, vulnerability, and resilience. In Managing the Risks of Extreme Events and Disasters to Advance Climate Change Adaptation: Special Report of the Intergovernmental Panel on Climate Change. Cambridge: Cambridge University Press, pp. 25-64. [CrossRef]

Lei, Yongdeng, Jing'ai Wang, Yaojie Yue, Hongjian Zhou, and Weixia Yin. 2014. Rethinking the relationships of vulnerability, resilience, and adaptation from a disaster risk perspective. Natural Hazards 70: 609-27. [CrossRef]

Li, Min, Yuji Hasemi, and Yuna Nozoe. 2019. Study on disaster risks and countermeasures influenced by the impact of the modernization process in historical mountain villages: A case study of Hanazawa historical village, Japan. International Journal of Disaster Risk Reduction 41: 101290. [CrossRef]

Lin, Le, Ying Wang, and Tianxue Liu. 2017. Perception of recovery of households affected by 2008 Wenchuan earthquake: A structural equation model. PLoS ONE 12: e0183631. [CrossRef] [PubMed]

Lin, Mau-Roung, Wenzheng Huang, Chingchaw Huang, Hei-Fen Hwang, Lung-Wen Tsai, and Yun-Ning Chiu. 2002. The impact of the Chi-Chi earthquake on quality of life among elderly survivors in Taiwan-a before and after study. Quality of Life Research 114: 379-88. [CrossRef] 
Maskrey, Andrew. 2011. Revisiting community-based disaster risk management. Environmental Hazards 10: 42-52. [CrossRef]

Mavromatidi, Asimina, Elodie Briche, and Cécilia Claeys. 2018. Mapping and analyzing socio-environmental vulnerability to coastal hazards induced by climate change: An application to coastal Mediterranean cities in France. Cities 72: 189-200. [CrossRef]

Medina Pérez, Patricia Catalina, Sonia Bass Zavala, and César Mario Fuentes Flores. 2019. Herramientas para el diseño de una política social. INVI 34: 197-223. Available online: https://revistainvi.uchile.cl/index.php/INVI/article/view/63088 (accessed on 25 August 2021).

Milanés Batista, Celene, and Claudio Fabian Szlafsztein. 2018. Experiencias Metodológicas para la Gestión del Riesgo. Educosta: Barranquilla.

Milanes, Celene B., Marina B. Martínez-González, Jorge Moreno-Gómez, Ana Saltarín J., Andres Suarez, Samuel E. Padilla-Llano, Alex Vasquez, Allan Lavell, and Seweryn Zielinski. 2021. Multiple hazards and governance model in the Barranquilla Metropolitan Area, Colombia. Sustainability 13: 2669. [CrossRef]

Nathan, Fabien. 2008. Risk perception, risk management and vulnerability to landslides in the hill slopes in the city of La Paz, Bolivia. A preliminary statement. Disasters 323: 337-57. [CrossRef] [PubMed]

Leary, Neil, Cecilia Conde, and Jyoti Kulkarni. 2008. Climate Change and Vulnerability. London: Earthscan.

Padilla-Llano, Samuel. 2015. Producción de Espacio Público [X] Participación Ciudadana. El Proyecto de Espacio Público Resultado de Procesos de Participación Ciudadana. Available online: http:/ /hdl.handle.net/10803/309288 (accessed on 25 August 2021).

Padilla-Llano, Samuel. 2020. From the urban project to the participative public space project: A historical approach. Módulo Arquitectura CUC 24: 67-82. [CrossRef]

Pardo Martínez, Clara I. 2018. Climate change in Colombia: A study to evaluate trends and perspectives for achieving sustainable development from society. International Journal of Climate Change Strategies and Management 10: 632-52. [CrossRef]

Peters, Jeff, Nathan Wood, Rick Wilson, and Kevin Miller. 2016. Intra-community implications of implementing multiple tsunamievacuation zones in Alameda, California. Natural Hazards 84: 975-95. [CrossRef]

Rehman, Junaid, Osama Sohaib, Mohammad Asif, and Biswajeet Pradhan. 2019. Applying systems thinking to flood disaster management for a sustainable development. International Journal of Disaster Risk Reduction 36: 10101. [CrossRef]

Remesar, Antoni, Xavi Salas, Samuel Padilla, and Danae Esparza. 2012. Inclusion and empowerment in public art and urban design On the W@terfront 24: 3-32. Available online: https://raco.cat/index.php/Waterfront/article/view/259235 (accessed on 25 August 2021).

Romero De Gutiérrez, Laineth. 2018. De la Regeneración Urbana a la Gentrificación. Caso Estudio en Barranquilla. Colombia Thesis Doctoral, Universidad de Granada, Granada, Spain. Available online: http://digibug.ugr.es/handle/10481/50914 (accessed on 25 August 2021).

Sandoval Díaz, José Sebastián, Luisa Rojas Paez, Makarenna Villalobos Soublet, Constanza Sandoval Díaz, Francisco Moraga, and Nayssa Aguirre. 2018. De la organización vecinal hacia la gestión local del riesgo: Diagnóstico de vulnerabilidad y capacidad. INVI 3392: 155-80. [CrossRef]

Sarmiento, Juan Pablo, and Ana María Torres-Muñoz. 2020. Risk Transfer for Populations in Precarious Urban Environments. International Journal of Disaster Risk Science 11: 74-86. [CrossRef]

Scolobig, Anna, Tim Prior, Dagmar Schröter, Jonas Jörina, and Anthony Patta. 2015. Towards people-centred approaches for effective disaster risk management: Balancing rhetoric with reality. International Journal of Disaster Risk Reduction 12: 202-12. [CrossRef]

Silver, Jonathan, Cheryl McEwan, Laura Petrella, and Hamidou Baguian. 2013. Climate change, urban vulnerability and development in Saint-Louis and Bobo-Dioulasso: Learning from across two West African cities. Local Environment 186: 663-77. [CrossRef]

Tyler, Stephen, and Marcus Moench. 2012. A framework for urban climate resilience. Climate and Development 44: 311-26. [CrossRef]

UNFPA. 2018. The State of the World Population 2018. New York: UNFPA.

Wang, Xiangdong, Lan Gao, Huabiao Zhang, Chengzhi Zhao, Yucun Shen, and Naptaka Shinfuku. 2000. Post-earthquake quality of life and psychological well-being: Longitudinal evaluation in a rural community sample in northern China. Psychiatry and Clinical Neurosciences 544: 427-33. [CrossRef] [PubMed]

Zanetti, Vitor B., Wilson C. De Sousa Junior, and Débora M. De Freitas. 2016. A climate change vulnerability index and case study in a Brazilian coastal city. Sustainability 8: 811. [CrossRef]

Xu, Dingde, Yi Liu, Xin Deng, Chen Qing, Linmei Zhuang, Zhuolin Yong, and Kai Huang. 2019. Earthquake Disaster Risk Perception Process Model for Rural Households: A Pilot Study from Southwestern China. International Journal of Environmental Research and Public Health 16: 4512. [CrossRef]

Yoo, Gayoung, Jin Hwan Hwang, and Choongik Choi. 2011. Development and application of a methodology for vulnerability assessment of climate change in coastal cities. Ocean $\mathcal{E}$ Coastal Management 547: 524-34. [CrossRef]

Zhou, Yang, Ning Li, Wenxiang Wu, Jidong Wu, and Peijun Shi. 2014. Local Spatial and Temporal Factors Influencing Population and Societal Vulnerability to Natural Disasters. Risk Analysis 344: 614-39. [CrossRef] [PubMed] 